\title{
The Rarest of Rare Penile Carcinomas: In Situ and Invasive Nodular Penile Melanomas on the Same Patient Clinical Case and Systematic Review
}

\author{
Pablo Doménech López ${ }^{1 *}$, Jose Enrique Robles García ${ }^{1}$, Juan Colombás Vives ${ }^{1}$, Cristina

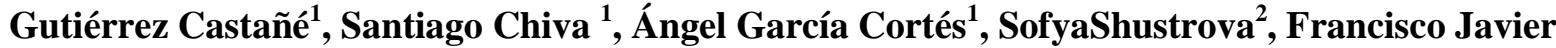 \\ Ancizu Marckert ${ }^{1}$, Jose Joaquín Paricio Martínez ${ }^{3}$, Marta Abengózar Muela ${ }^{3}$, Guillermo \\ Barbas Bernardos ${ }^{1}$, Marcos Torres Roca ${ }^{1}$, Guillermo Andrés Boville ${ }^{1}$, Fernando Ramón de Fata \\ Chillón ${ }^{1}$, Felipe Villacampa Aubá ${ }^{1}$, David Rosell Costa ${ }^{1}$, Fernando Diez-Caballero Alonso ${ }^{1}$, \\ Bernardino Miñana López ${ }^{1}$, Ignacio Pascual Piedrola ${ }^{1}$ \\ ${ }^{l}$ Clínica Universidad de Navarra (Urologydepartment) \\ ${ }^{2}$ Universidad de Navarra \\ ${ }^{3}$ Clínica Universidad de Navarra (Pathologicalanatomydepartment)
}

*Corresponding Author: Pablo Doménech López, Clínica Universidad de Navarra, Urologydepartment, Pío XII avenue, Spain, Email: pdomenech@unav.es

\begin{abstract}
Introduction: Primary melanoma of the penile urethra and glans is a rare condition that accounts for less than $2 \%$ of all penile tumours, composes only $0.1 \%$ of total melanomas.

Because of its great rarity, thisclinical case presentation is considered noteworthy for the scientific community, providing an exhaustive review of this pathology.
\end{abstract}

Method: A literature search using PubMed search engine was conducted analysing latest reviews from the last 10 years using the terms "glans melanoma". Only 18 results were found, most of them being published as case report.

Second search is performed using the terms "urethra melanoma", founding 7 review articles on the last 10 years in males. Although not all articles meet the requirements, and half of them are the same found in prior search.

Finally, theoretical and epidemiology articles were selected in order to provide anatomical base and dermatological information.

Results: 85-year-old male is diagnosed with melanoma in situ in glans and urethra by cold biopsy.

The treatment includes total penectomywith perineal urethrostomyand bilateral inguinal laparoscopic lymphadenectomy.

Conclusions: The risk factors for this type of pathology are not fully identified, so the follow-up of pigmented lesions in this area should be carried outby a specialist.

Even though there is no consensus on melanoma, surgery is considered to be the first option with curative intention in localized tumours, though staging must be completed due their rapid dissemination and late diagnosis if there is no clinical suspicion. In the case of distant metastasis, the treatment does not differ from any other metastatic melanomas, where chemotherapy and immunotherapy are the cornerstone of the treatment.It is necessary to go in depth inthese clinical cases to elaborate clear guidelines for this pathology.

Keywords: Melanoma; glans melanoma; surgical treatment; in situ melanoma; mucosal melanoma.

\section{INTRODUCTION}

Primary penile melanoma is a rare condition that accounts for less than $2 \%$ of penile tumours [1].
According to the data from the Spanish Society of Medical Oncology (SEOM), 2376 men were diagnosed with melanoma in our country in 
2018 , representing $1.7 \%$ of the total tumours diagnosed [2].

It is considered that $95 \%$ are from cutaneous origin and only $5 \%$ are mucosal.

Considering that penile melanomas correspond to less than $0.1 \%$ of all melanomas [3], we can suppose that the annual appearance of penile melanoma in our country is of 2 cases at most. Given that both penile melanomas and mucosal melanomas are very infrequent, the occurrence of mucosal penile melanoma is even less common. Considering that more than An 85year-old male with no past urological history was evaluated by his dermatologist because of a pigmented lesion in the glans penisin 2017, where his doctor performed a biopsy that had no malignancy signs in the sample.

half of penile melanomas appear in the glans penis [4], in case of suspicion, this type of lesions should be evaluated and followed.

The primary urethral tumour is considered rare due to its low incidence, being less than $1 \%$ of new tumours diagnosed [5]. The incidence of melanoma in this location is also uncommon, together with sarcoma representing $5 \%$ of total ureteral tumours [6]. Also, primary urethral carcinoma incidence is twice as frequent in women [7].
Penile melanoma in situis consideredan even more extraordinary entity [8], so the probability of this pathology affecting even only one person in our country during an entire year is very low according to the available data.

\section{Method}

A literature search using PubMed search engine was conducted analysing latest reviews from the last 10 years using the terms "glans melanoma". Only 18 results were found, most of them being published as case report. Second search is performed using the terms "urethra melanoma", founding 7 review articles on the last 10 years in males. Although not all articles meet the requirements, and half of them are the same found in prior search.

Finally, theoretical and epidemiology articles were selected in order to provide anatomical base and dermatological information.

\section{Clinical case}

The patient started with topical treatment of the lesion, being monitored until May 2019, where the lesion presented ulcerative appearance, involving coronal sulcus and urethra.

Because of this, a second biopsy was performed, reporting melanoma in situ, and the patient was referred to Urology (fig 1).

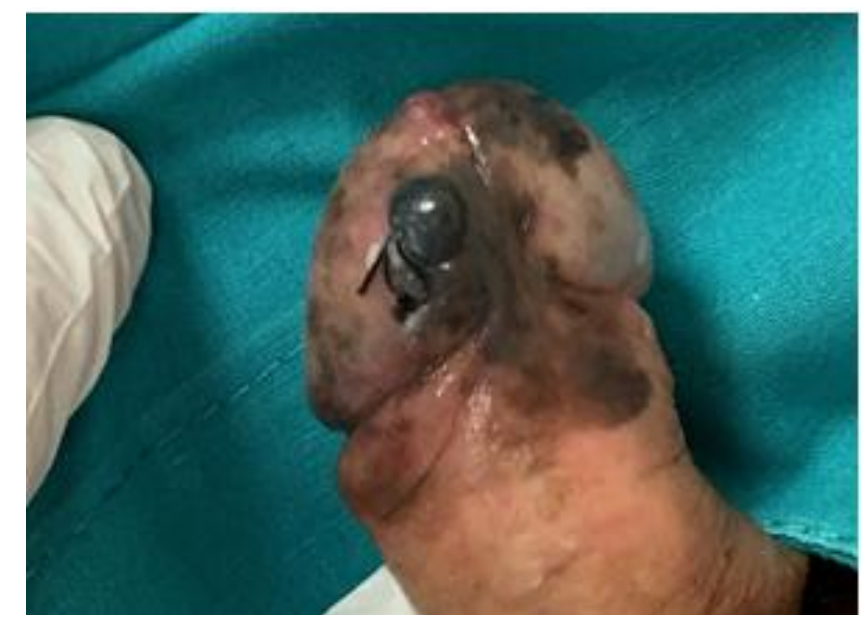

Fig1: Glanspenis melanoma

There has been no pain or discomfort in relation to the injury or bleeding prior to the biopsy.

An extension study was performed using a CT scan, reporting no signs of lymph node or metastatic involvement.

\section{DISCUSSION}

The risk factors for this type of pathology are not fully identified [3,9, and 10], so the follow- up of pigmented lesions in this area should be carried out by a specialist.

There are signs that can help with the early detection of penile melanoma such as ulceration in $39 \%$ of the cases, or haematuria in up to $69 \%$ of the cases of ureteral melanoma [3]. Nevertheless, the diagnosis is usually late, and as $20 \%$ of the patients will present lymph node 
involvement $[11,12]$, the biopsy is necessary to complete the staging (13).

The first diagnosis of penile melanoma was conducted in 1859 by Muchinson (14).

A review carried out in 2014 by Dino Papeš et al. [3] reported a total of 129 articles and 220 patients with primary melanoma of the penis and urethra from 1962 to 2012, with an average age of 65 years.

Multiple therapeutic options have been proposed with no clear action guidelines against penile melanoma [15], although it seems clear that the first stage in the treatment should be surgery [8, $16]$.

There is a wide range of indications for treatment extension in localized tumours, starting from the local lesion removal to the radical penectomy with lymphadenectomy.

The involvement of the urethra and pathological anatomy report of melanoma in situare considered risk factors for poor clinical evolution, so radical treatment is the first option to be considered in these cases $[17,18]$. The nodular melanoma has also been associated with more aggressive behaviour [19].

In addition, surgery is the first curative treatment option in localised tumours a priori [20] and complete removal of the primary lesion is the best prognostic factor for the patient's survival [21]. In our case, due to the pathological anatomy report of melanoma in situ, the curative treatment with radical surgery was chosen, consisting in the first stage of total penectomywith perineal urethrostomy (fig 2).

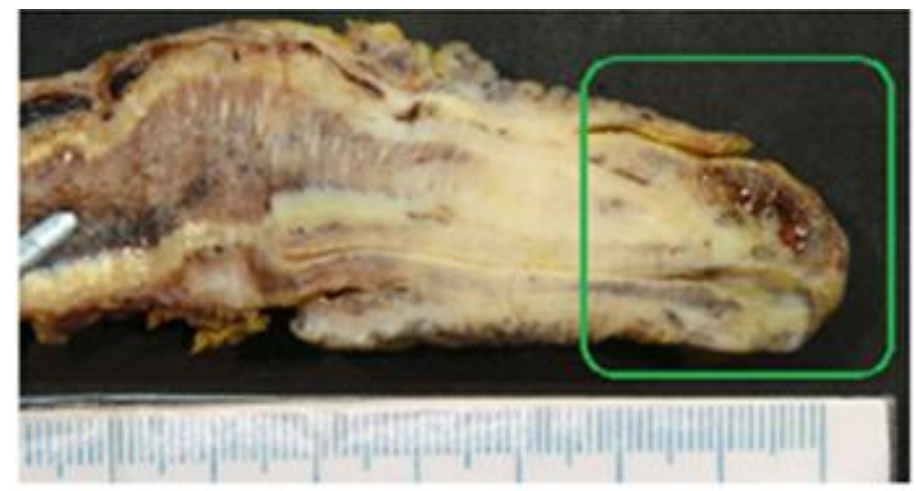

Fig2: Glas penismacroscopicslice

The pathological anatomy reports two foci of invasive nodular melanoma, ulcerated and $2.6 \mathrm{~mm}$ thick, separated from each other by

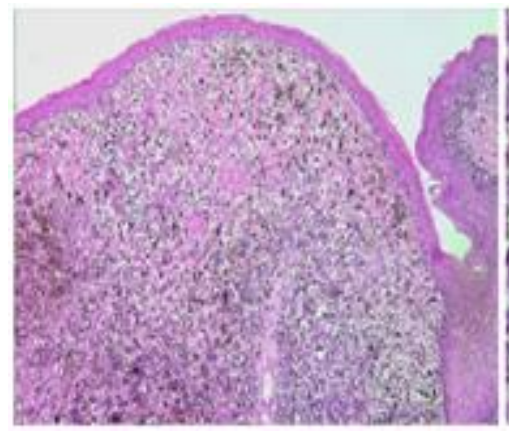

$5 \mathrm{~mm}$. In addition, multiple foci of melanoma in situ were found at the level of the coronal groove and urethra (fig 3).

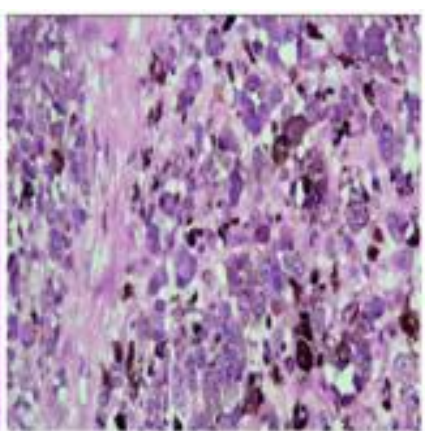

Fig3: 1) Hex4 Infiltrating neoplasm of nodular architecture. 2) Hex20 Large, epithelioid cells with and irregular nucleus and prominent nucleolus. They usually have dense intracytoplasmic granules of melanin.

Due to unfavourable anatomy, it is decided to complete the staging by bilateral inguinal lymphadenectomy, performed by Videos copy 4 weeks after the first intervention.

Inguinal lymphadenectomy using minimally invasive techniques is a safe procedure with much lower morbidity than open lymphadenectomy [22]. Also, patients with penile primary tumours exhibiting unfavourable histologic features are strongly recommended to complete the staging because of a higher risk of metastasis [16], so the use of Videos copy seems appropriate in this case.

Staging of the melanoma of the glans penis has traditionally been based on a system developed by Bracken et al. [23], with stage I disease 
confined to the penis, stage II being metastatic to the regional lymph nodes and stage III representing disseminated disease.

In the case presented, no tumour involvement was observed in any of the lymph nodes analysed,

classifying it as a stage I, although according to AJCC, being $2.6 \mathrm{~mm}$ thick makes it T3NOM0, representing stage II.

In any case, it is important to remember that in primary urethral melanomas the thickness of Breslow is not as precise, so it is advisable to apply Levine staging [24], used by other researchers.

Complementary treatments used in melanoma include radiotherapy, chemotherapy and immunotherapy.

There is no clear increase in overall survival found with adjuvant radiotherapy [25], although it is reported to be useful as a palliative treatment for local disease control [26].

The role of chemotherapy in mucosal melanoma is undefined [10], although targeted therapies have shown abetter response due to mutations developed by this type of tumours in cases of advanced or metastatic disease.

The best-known mutation corresponds to KIT oncogene, where Imatinib treatment is useful in cases of mutations or amplifications of the gene [21]. Other drugs of the same family have also proven to be effective in some cases [27].

Other treatments evaluated are those based on BRAF inhibition, where combined therapy is the best option [28].

At last, immunotherapy has shown a possible response in mucosal melanoma (29), although the evidence is not clear. In cutaneous melanoma, the use of PD-1 and anti-CTLA-4 inhibitors has revolutionized the treatment [30], but there is no significant data in mucosal melanoma.

\section{CONClusion}

Even though there is no consensus on melanoma, surgery is considered to be the first option with curative intention in localized tumours, though staging must be completed due their rapid dissemination and late diagnosis if there is no clinical suspicion.

In the case of distant metastases, the treatment does not differ from any other metastatic melanomas, where chemotherapy and immunotherapy are the cornerstone of the treatment. Radiotherapy is reported to be usefulas a palliative treatment for local control of the disease when surgery is not an option.

Immunotherapy seems to be the most promising research pathway in this type of melanoma, although it is necessary to go in depth in these cases to elaborate clear guidelines for mucosal melanomas.

\section{REFERENCES}

[1] Stillwell TJ, Zincke H, Gaffey TA, Woods JE: Malignant melanoma of the penis. J Urol 1998, 140:72-75

[2] SEOM Sociedad Española de Oncología Médica. Las cifras del Cáncer en España 2018. https://seom.org/seomcms/images/stories/recurs os/Las_Cifras_del_cancer_en_Espana2018.pdf. Depósito Legal: M-3161-2018 (C) 2018. Sociedad Española de Oncología Médica (SEOM)

[3] DinoPapeš, Silvio Altarac, NuhiArslani, ZoranRajković, AnkoAntabak, MarkoĆaćić. Melanoma of the Glans penis and Urethra. Urology; Volume 83, issue 1, January 2014, Pages 6-11

[4] Demitsu T, Nagato H, Keiko $N$, et al. Melanoma in situ of the penis. J Am AcadDermatol 2000; 42:386-8.

[5] Gatta, G., et al. Rare cancers are not so rare: the rare cancer burden in Europe. Eur J Cancer, 2011. 47: 2493

[6] Swartz MA, Porter MP, Lin DW, et al. Incidence of primary urethral carcinoma in the United States. Urology. 2006; 68:1164-1168.

[7] Papeš D, Altarac S. Melanoma of the female urethra. Med Oncol. 2013; 30:329.

[8] Baraziol R, Schiavon M, Fraccalanza E, De Giorgi G. Melanoma in situ of penis: a very rare entity: A case report and review of the literature. Medicine (Baltimore). 2017 Sep; 96 (36):e7652.

[9] Brady KL, Mercurio MG, Brown MD. Malignant tumors of the penis. DermatolSurg 2013; 39:527-47.

[10] Spencer K.R., Mehnert J.M. (2016) Mucosal Melanoma: Epidemiology, Biology and Treatment. In: Kaufman H., Mehnert J. (eds) Melanoma. Cancer Treatment and Research, vol 167. Springer, Cham

[11] vanGeel AN, den Bakker MA, Kirkels W, et al. Prognosis of primary mucosal penile melanoma: a series of 19 Dutch patients and 47 patients from the literature. Urology. 2007; 70: 143-147. 
The Rarest of Rare Penile Carcinomas: In Situ and Invasive Nodular Penile Melanomas on the Same Patient Clinical Case and Systematic Review

[12] Oldbring J, Mikulowski P. Malignant melanoma of the penis and male urethra. Report of nine cases and review of the literature. Cancer. 1987; 59:581-587.

[13] Lucia MS, Miller GJ. Histopathology of malignant lesions of the penis. UrolClin North Am 1992;19:227-46

[14] Gross SD. A System of Surgery. 6th ed. Philadelphia: W.B.Saunders; 1882

[15] Bittar JM, Bittar PG, Wan MT, Kovell RC, Guzzo TJ, Shin TM, Etzkorn JR, Sobanko JF, Miller CJ. Systematic review of surgical treatment and outcomes after local surgery of primary cutaneous melanomas of the penis and scrotum. Dermatol. Surg. 2018 Sep; 44(9): 11 59-1169.

[16] Campbel-Walhs Urology. Seventh Edition. Part Vi Male Genitalia. Chapter Tumors of the penis. Page 863

[17] Velazquez EF, Ayala G, Liu H, et al. Histologic grade and perineuralinvasión are more important tantumor thickness as predictor of nodal metástasis in penile squamous cell carcinoma infading 5 to $10 \mathrm{~mm}$. Am J Pathol 2008;32:974-9

[18] De Giorgi V, Grazzini M, Massi D, Rossari S, Gori A, Janowska A, Bruscino N, Lotti T: Melanoma of the penis: a clinical dermoscopic case study. ActaDermVenereol 2010, 90:87-88.

[19] Mar V, Roberts H, Wolfe R, et al. Nodular melanoma: A distinct clinical entity and the largest contributor to melanoma deaths in Victoria, Australia. J Am AcadDermatol. 2013; 68:568-575.

[20] Fenn NJ, Johnson RC, Sharma AK, Attanoos RL, Horgan K: Malignant melanoma of the penis. Eur J SurgOncol 1996, 22:548-549

[21] Seetharamu N, Ott PA, Pavlick AC. Mucosal melanomas: a casebased review of the literature. Oncologist. 2010; 15:772-781.

[22] M. Alvarez-Maestro, E. RiosGonzalez, L. Martinez-Piñeiro, F.J. SanchezGomez. Modified Endoscopic Left Inguinal Lymphadenectomy. Actas Urol Esp. 2013 NovDec; 37(10):663-6.
[23] Bracken RB, Diokno AC: Melanoma of the penis and urethra: 2 case reports and review of the literature. J Urol 1974, 111:198-200

[24] Levine RL. Urethral cancer. Cancer. 1980; 45: 1965-1972.

[25] Carvajal RD, Spencer SA, Lydiatt W (2012) Mucosal melanoma: a clinically and biologically unique disease entity. J Natl Compr Cancer Netw JNCCN 10(3):345-356

[26] Mihajlovic M, Vlajkovic S, Jovanovic P, Stefanovic V (2012) Primary mucosal melanomas: a comprehensive review. Int $\mathbf{J}$ ClinExpPathol 5(8):739-753

[27] Woodman SE, Davies MA (2010) Targeting KIT in melanoma: a paradigm of molecular medicine and targeted therapeutics. BiochemPharmacol 80(5):568-574.

[28] Long GV, Stroyakovskiy D, Gogas H, Levchenko E, de Braud F, Larkin J, Garbe C, Jouary T, Hauschild A, Grob JJ, ChiarionSileni V, Lebbe C, Mandala M, Millward M, Arance A, Bondarenko I, Haanen JB, Hansson J, Utikal J, Ferraresi V, Kovalenko N, Mohr P, Probachai V, Schadendorf D, Nathan P, Robert C, Ribas A, DeMarini DJ, Irani JG, Casey M, Ouellet D, Martin AM, Le N, Patel K, Flaherty K (2014) Combined BRAF and MEK inhibition versus BRAF inhibition alone in melanoma. $\mathrm{N}$ Engl J Med 371(20):1877-1888

[29] Postow MA, Luke JJ, Bluth MJ, Ramaiya N, Panageas KS, Lawrence DP, Ibrahim N, Flaherty KT, Sullivan RJ, Ott PA, Callahan MK, Harding JJ, D’Angelo SP, Dickson MA, Schwartz GK, Chapman PB, Gnjatic S, Wolchok JD, Hodi FS, Carvajal RD (2013) Ipilimumab for patients with advanced mucosal melanoma. Oncologist 18(6):726-732.

[30] Topalian SL, Sznol M, McDermott DF, Kluger HM, Carvajal RD, Sharfman WH, Brahmer JR, Lawrence DP, Atkins MB, Powderly JD, Leming PD, Lipson EJ, Puzanov I, Smith DC, Taube JM, Wigginton JM, Kollia GD, Gupta A, Pardoll DM, Sosman JA, Hodi FS (2014) Survival, durable tumor remission, and longterm safety in patients with advanced melanoma receiving nivolumab. J ClinOncol 32(10):1020-1030.

Citation: DoménechLópez, Robles García, ColombásVives, Gutiérrez Castañé et.al, The Rarest of Rare Penile Carcinomas: In Situ and Invasive Nodular Penile Melanomas on the Same Patient Clinical Case and Systematic Review. ARC Journal of Urology. 2020; 5(1):10-14.DOI: https://doi.org/ 10.20431/2456-060X. 0501003.

Copyright: (c) 2020 Authors. This is an open-access article distributed under the terms of the Creative Commons Attribution License, which permits unrestricted use, distribution, and reproduction in any medium, provided the original author and source are credited. 